\title{
Telehealth at Home: Co-Designing a Smart Home Telehealth System
}

\author{
Inga HUNTER ${ }^{a}$ Phoebe ELERS ${ }^{\mathrm{b}}$ Caroline LOCKHART ${ }^{\mathrm{a}}$, Hans GUESGEN ${ }^{\mathrm{c}}$ Dick \\ WHIDDETT ${ }^{\mathrm{a}}$ and Amardeep SINGH ${ }^{\mathrm{c}}$ \\ ${ }^{a}$ School of Management, Massey Business School, Massey University, New Zealand \\ ${ }^{\mathrm{b}}$ School of Communication, Journalism and Marketing, Massey Business School, \\ Massey University, New Zealand \\ ${ }^{c}$ School of Fundamental Sciences, College of Science, Massey University, New Zealand
}

\begin{abstract}
Increasing life expectancy and rates of chronic conditions place increasing demands on aged care health and support services. One response preferred by older adults and seen as cost effective is aging in place, whereby older people remain in their own homes and avoid aged residential care. For this to take place, it is crucial that older people maintain effective relationships with support networks and that older adults and these networks have adequate information to support patient centred health and wellness care at home. This study explored how smart home telehealth, a form of telehealth where health care is provided at a distance using smart home digital technology (sensors), could assist older people to age in place and enhance their health and wellbeing. It was a two-phase project, preceded by a workshop with experts:1) 41 interviews with older adults and their informal support networks, seven focus groups with 44 health providers working with older adults, which informed 2) a pilot implementation of a co-designed telehealth system, addressing key barriers identified in Phase 1. The system used low cost, easily accessible, and commercially available sensors, transferring information via email and/or text messaging. It was successfully piloted with five older adults and twelve of their respective support networks for six months, who reported an increased feeling of security and improved interpersonal communication. The findings indicate that smart home telehealth could assist aging in place, and the study provides insights into successful co-design of smart home telehealth services at scale that could be implemented and deployed in contexts wider than aged care.
\end{abstract}

Keywords. Aging in place; smart home technology, telehealth, wellness

\section{Introduction}

Telehealth is the use of information or communication technology to deliver health or medical care from a distance. Key areas include telemedicine, telemonitoring and mHealth [1]. Smart home telehealth is a form of telehealth monitoring, where telehealth is combined with smart home technologies such as sensors [2,3]. It enables health and wellness information to be collected passively within the home rather than at health care organisations and facilitates the transmission of that information to relevant care providers. It makes the collection and sharing of health and wellness information accessible to a much greater proportion of the population and locations.

Alongside increasing life expectancy in New Zealand (NZ) [4], in line with other developed countries [5], more people are living longer in poor health, with multiple co-

${ }^{1}$ Corresponding Author, Inga Hunter, School of Management, Massey Business School, Massey University, New Zealand; E-mail: I.Hunter@massey.ac.nz 
morbidities [6], challenging health systems to provide sustainable health care services. Policy makers in New Zealand strongly support a patient-focused integrated primary care approach in which the older adult (OA) is supported by formal and informal support networks to remain in their community in the place they call home, a policy supported by OAs and known as ageing in place [6-9].

Aging in place is dependent on both informal carers (support networks such as family, whānau, friends, neighbours, etc) and formal carers (health providers). This support by informal carers accounts for $50-90 \%$ of the long-term support of OAs [10] and most have limited access to formal support services [11]. The study is underpinned by the Structural Model of Actors developed for this study (illustrated in Figure 1). It emphasizes individualized care by placing the OA at the centre surrounded by two layers of support networks that enable aging in place; an inner layer of informal support networks who provide informal practical and emotional support, and an outer layer of formal support networks, comprising health providers.

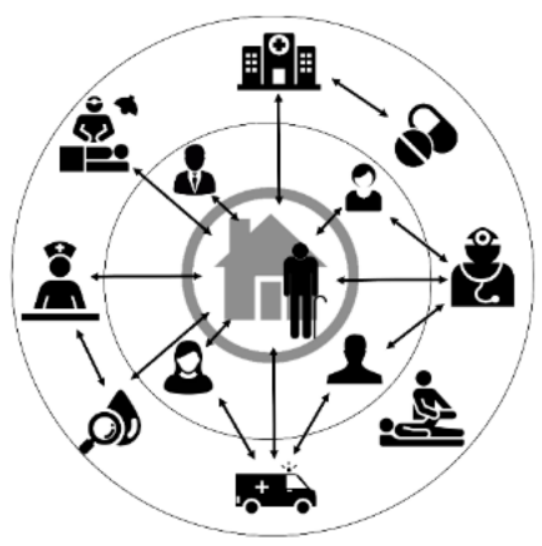

Figure 1. Structural Model of Actors

The inclusion of the informal support layer emphasises the increased complexity of these new models of care in comparison to the more traditional dyadic patientpractitioner situation. It explicitly recognizes the changing roles and relationships and information exchanges which take place, including those between the formal and informal support networks, and highlights that these relationships can be separated by distance (and indeed by time). Significantly, as the arrows in Figure 1 indicate, the model would allow one-to-one, one-to-many, and many-to-many communication streams. Telehealth, by its very design, is ideally placed to enable and support these different communication streams. In the model, smart home telehealth systems would enable information collected by smart home technologies to be communicated through digital technologies (laptops, computers, mobile devices, email, texting, video chat, etc), using information communication technologies (wifi, bluetooth, internet, etc) across the different actors.

Smart home technologies have been used to support OAs as they age in place for some time. They may range from simple home monitoring sensors [12] to purpose-built smart homes with complex sensor setups including voice activation and intelligent cognitive assistants $[13,14]$, however the simple basic unit is a sensor. Sensors can be 
wearable, ambient, or robotic, with multiple sensor deployment, the commonest use of sensors [15]. Figure 2 lists different types of sensors currently available (in no particular order). Hence, it is a potentially complicated field for OAs to understand.

\begin{tabular}{|c|c|c|}
\hline $\begin{array}{l}\text { Ambient (embedded into daily } \\
\text { environment) }\end{array}$ & Wearable (anywhere on-body) & $\begin{array}{l}\text { Robotic (could include sensors } \\
\text { from wearable and ambient) }\end{array}$ \\
\hline Passive infrared (PIR) motion & Biosensors & Biosensors \\
\hline Video & Accelerometer (tri-axial) & Tablet \\
\hline Pressure & Barometic pressure/altimeter & Camera \\
\hline Force & Gyroscope & Accelerometer \\
\hline Smoke and flame & Velocity & Velocity \\
\hline Humidity & Magnetic forces & Barometric pressure \\
\hline Luminescence & Video (ego-centric) & Microphones \\
\hline Sound & Microphones & Panic buttons \\
\hline Water flow & Step counters & GPS trackers \\
\hline Water temperature & Panic buttons & Movable 'arms', 'legs', 'limbs' \\
\hline Floor sensors & Fitness trackers (Fitbit, etc) & \\
\hline Pressure mat sensors & GPS trackers & \\
\hline $\begin{array}{l}\text { Radar sensors (both doppler and } \\
\text { ladar) }\end{array}$ & Hearing aids & \\
\hline Magnetic switches, & Pocket talker & \\
\hline Temperature detectors & AR (MS Hololens) & \\
\hline CO2 concentration sensors & Smart clothing (socks, shoes, vest, T-shirt & \\
\hline Gas concentration sensors & Wearable tattoos & \\
\hline \multicolumn{3}{|l|}{ Electricity use } \\
\hline RFID & Sensors can be combined: & \\
\hline Eye trackers & $\begin{array}{l}\text { Smart wristband (combines activity } \\
\text { tracker, sleep, heart rate) }\end{array}$ & \\
\hline Kinect and Wii (creates silhouettes) & $\begin{array}{l}\text { Smart phones (often contain some of } \\
\text { these sensors) }\end{array}$ & \\
\hline Vibration and vibro-tactile & $\begin{array}{l}\text { Smart watches (also can contain multiple } \\
\text { sensors) }\end{array}$ & \\
\hline Contact detection & $\begin{array}{l}\text { Gamification using sensors, apps and data } \\
\text { input screens }\end{array}$ & \\
\hline \multicolumn{3}{|l|}{ Visitor-counting } \\
\hline \multicolumn{3}{|l|}{ silicon photomultipliers (SiPMs) } \\
\hline \multicolumn{3}{|l|}{360 degree lamp } \\
\hline Float sensor (for toilet) & \multicolumn{2}{|c|}{$\begin{array}{l}\text { Biosensors can measure heart rate, body temperature, oxygen saturation, } \\
\text { respiration rate, electrocardiogram, blood glucose, blood pressure, } \\
\text { perspiration, heart sounds, electromyogram }\end{array}$} \\
\hline Human activity recognition (HAR) & & \\
\hline
\end{tabular}

Figure 2. Sensor types [15] (reproduced with permission)

Smart home technologies are often underutilized [16], and there are known barriers to uptake among OAs, including privacy, cost, and unrecognised need [17,18]. Physical and cognitive decline may limit an OA's ability to use technology [16,17]. Wider organizational and financial barriers, and regulatory and legislative issues with adoption of digital health systems exist [19]. Specifically, in New Zealand, culturally safe data collection, data ownership and governance must be addressed [20]. Studies have tended to consider technical aspects of sensor use with OAs or in controlled situations which are unrepresentative of real-life in OA's homes and have not considered human aspects of use [15]. Thus, this study has taken a socio-technical systems approach, which recognizes that the adoption of new technologies involves interaction between society's complex infrastructures and human behaviour [21] and aimed to explore the barriers and user requirements for smart home telehealth systems for OAs living at home and to develop potential solutions. 


\section{Methodology}

This study was a two-phase project, preceded by a workshop with experts, consisting of 1) 41 interviews with OAs and their informal support networks, seven focus groups with 44 health providers working with OAs, which informed 2) a pilot implementation of a co-designed telehealth system, addressing key barriers identified in Phase 1 . The study procedures were approved by the Massey University Human Ethics Committee (SAO 16/65 and 17/32). Full details of the methodology and results of Phase 1 have been published elsewhere [22-24]. In brief, participants for Phase 1 were recruited using convenience sampling from people who expressed interest following promotion of the study by several community organisations. Older adults were aged 70 years or older, living alone in the study area (a provincial and semi-rural area) and had at least one chronic condition. Participating OAs self-identified two to four members of their informal support network. Ten OAs and 31 informal support network people participated in Phase 1. Older adults were aged 72-92 years; 8 were female and two male. Informal support network participants were 22-80 years old; 35 were female and six male.

From the Phase 1 participants, five OAs and twelve members of their respective informal support networks (SN) were recruited by convenience sampling to co-design a prototype system for each OA. This paper will focus on Phase 2 - co-designing a prototype smart home telehealth system individualised with each OA/SN grouping informed by the themes and derived user requirements from Phase 1. These user requirements are summarised in Table 1 [22].

Table 1. User Requirements Derived from the Inductive Analysis [22]

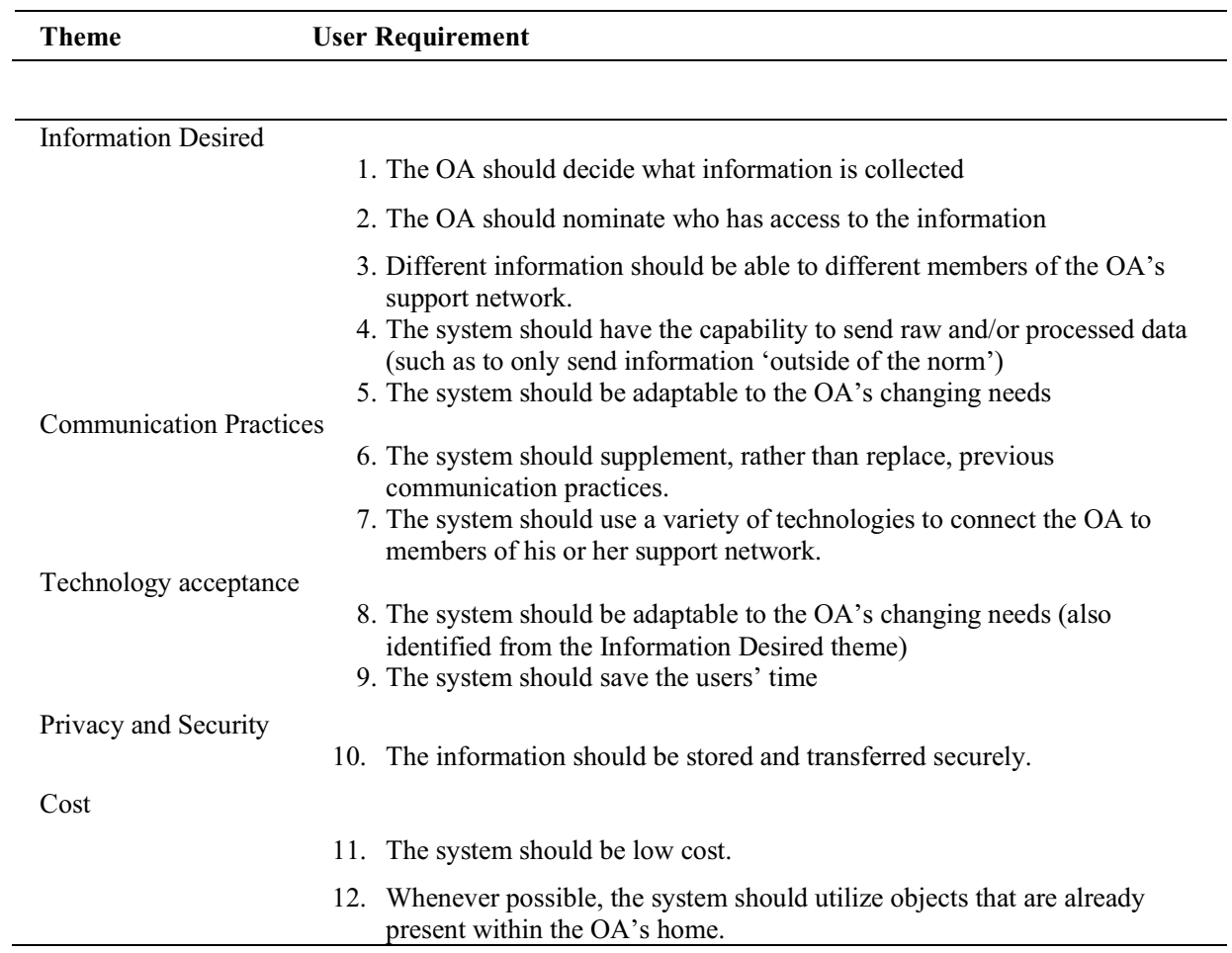


These requirements were used to inform decisions made during the system design such as selection of sensor types for the project (low cost, readily available, utilise objects already used in the home) and the OA determined which of these sensors they wanted to use, how they wanted them used, what data was collected and to whom it went. Privacy and security user requirements were met by a centralised hub that stored data on an SD card that did not leave the OA's home. Data collected was processed using a Raspberry Pi located within the central hub so that only 'information outside the norm' such as alerts were sent. In order not to impact on an existing phone or internet setup, the central hub also included a private network with a SIM card paid by the project. Open source software was used to keep costs low. Each prototype system was piloted by a member of the research team, and then installed in the respective OA's home. During the six-month trial period, a researcher engaged with OA and their SNs through phone calls, emails, text messaging, and personal visits. Individual systems were further customized by the research team using agile development as the OAs became more familiar with the possibilities around how the systems could support their activities of daily living. Examples of this are the medication reminder which was initiated in the 3rd month (for one OA) or where the initial setup did not meet the OAs requirements, such as the reminder light for another OA with low vision. One system was deliberately located in a rural setting to identify any additional issues due to rurality. For evaluation of the systemsystem availability, use of transmission networks, email and social media was determined from data traffic collected as part of the technical administration of each system and each OA and each SN completed a semi-structured interview with resultant thematic analysis.

\section{Results}

\subsection{Prototype Architecture}

Each system comprised of a smart-lightbulb and/or a multi-sensor (temperature, motion and luminescence) and/or a smart plug as well as a central control hub, which notified the SN members to contact or visit the OA if activities were outside of the norm (as defined by each OA and $\mathrm{SN}$ ). The $\mathrm{SN}$ members utilized a tablet and/or a smart phone to receive messages, which were sent passively (through the sensors). The central control device applied rules to evaluate data produced by the sensors, which could result in a message being sent to designated members of the older adult's support network.

The smart-plug could be activated to inform the control device when the appliance that it was connected to (such as a television or kettle) was turned on by the older adult (the devices selected were individualized to the OA). The sensor could inform the control device when it detects movement by the older adult (the locations of the sensors were individualized to each OA). The hours that these technologies functioned were also individualized to each OA. The smart-lightbulb could change colour to notify the older adult that there is an alert, such as the oven being left on, the room being too hot or cold, messages being sent to support network participants, and/or appointment reminders. The key aspect of the system was that the monitoring and any generated alerts were passive, the OAs did not have to initiate any action.

The OAs and their SNs had very little awareness or understanding of telehealth or smart home technologies prior to taking part in the study. During the study, as their level of understanding increased, they developed their own ideas for use of these technologies. 
Specific design elements raised by participants included each system to be configured according to the OAs self-reported routine and their desire for security; that their SN would be made aware if the OAs routine changed (for example 'they did not come in from the farm in the evening"); for safety, when they had forgotten to turn the element on the free-standing cooker off after one hour; for reminders (e.g. with taking medication) and therefore their SN would be notified of these exceptions to the OAs daily routine. An example scenario is shown in Figure 3 where temperature is tracked between $9 \mathrm{am}$ and $9 \mathrm{pm}$ with an alert sent to a SN if the temperature rises above 22 degrees.

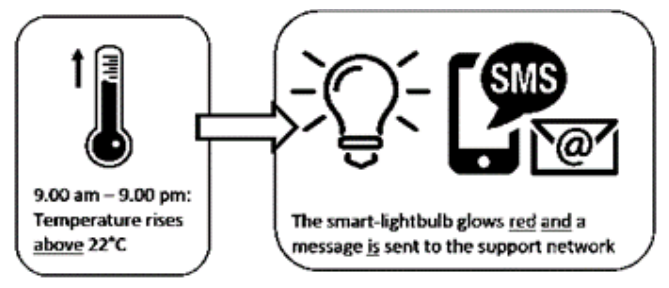

Figure 3. Example scenario

Meeting the user requirements and design elements raised some technical challenges, in particular with 1) interoperability - different sensors used different communication protocols (Wifi, Bluetooth, Z-wave), 2) stand-alone systems - energy efficient with low maintenance requirements, and 3) technical privacy constraints - different layers of communication between OAs and SNs, use of social media, and setting up a private network infrastructure within the home. These were addressed with a typical system consisting of a timer (for events), smart technology (sensors) and services (email, SMS and later Facebook), see Figure 4.

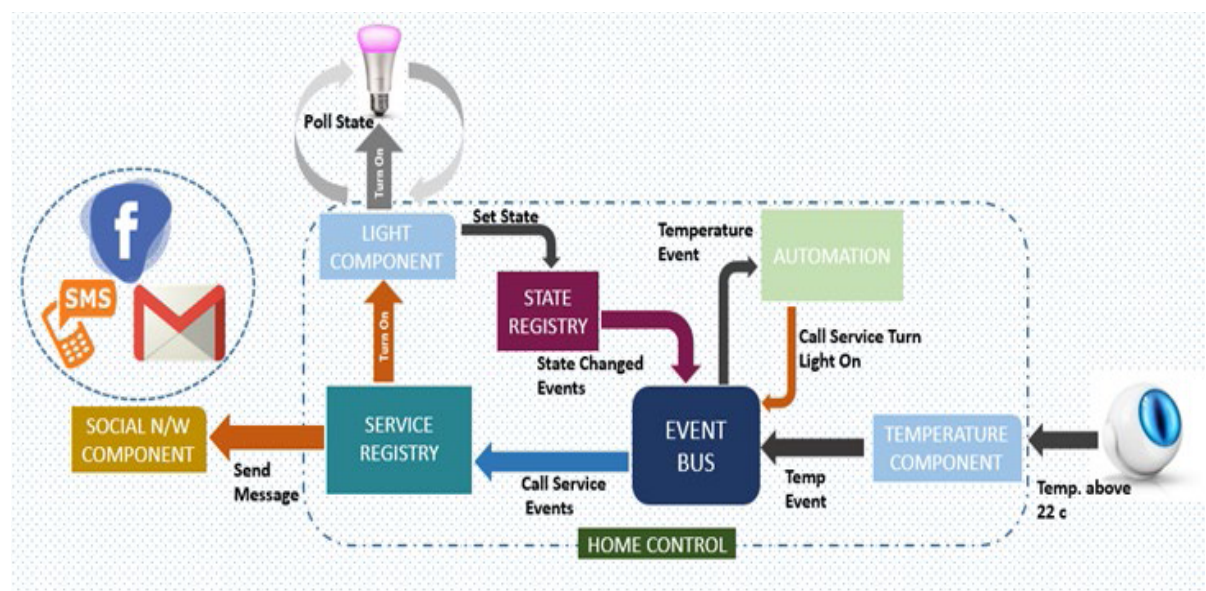

Figure 4. System architecture 


\subsection{Prototype Evaluation}

Two participants were unavailable to complete the final interview due to a deterioration in their health, hence thematic analysis involved 15 respondents (Table 2).

Table 2. Evaluation of prototype system - thematic analysis

\begin{tabular}{|c|c|c|c|}
\hline Theme & $\begin{array}{c}\text { \# Respondents } \\
\text { who agreed } \\
\text { or strongly } \\
\text { agreed }\end{array}$ & Comments & Notes \\
\hline $\begin{array}{c}\text { Improves } \\
\text { communication }\end{array}$ & $14 / 15$ & $\begin{array}{l}\text { 'Yes, we had good communication before, but this } \\
\text { made me call him more often if I got a message' (SN) } \\
\text { 'Communication with Mum definitely improved and } \\
\text { also communication between her support people' (SN) }\end{array}$ & $\begin{array}{c}\text { Remaining } \\
\text { respondent } \\
\text { was neutral. }\end{array}$ \\
\hline $\begin{array}{c}\text { Enhances } \\
\text { Relationships }\end{array}$ & $9 / 15$ & $\begin{array}{l}\text { 'Yes, it brought my two daughters into the mix when } \\
\text { before there was just the friend who I contacted daily' } \\
\text { (OA) } \\
\text { 'Yes, I think it did this. My sister and I would text about } \\
\text { where Mum was up to if we had texts' (from the system) } \\
(\mathrm{SN})\end{array}$ & $\begin{array}{l}\text { No-one } \\
\text { disagreed } \\
\text { and two did } \\
\text { not answer } \\
\text { this } \\
\text { question }\end{array}$ \\
\hline $\begin{array}{l}\text { Increased my } \\
\text { feeling of } \\
\text { security for the } \\
\text { OA's safety }\end{array}$ & $13 / 15$ & $\begin{array}{l}\text { 'Yes, knowing it's on as an alert is good first thing in } \\
\text { the morning. Plug + multi-sensor setup is ideal' (OA) } \\
\text { 'The system is very helpful as we can't always be there, } \\
\text { so if something is out of the ordinary it's comforting } \\
\text { knowing that we will be contacted' (SN) }\end{array}$ & $\begin{array}{c}\text { Two did not } \\
\text { answer this } \\
\text { question }\end{array}$ \\
\hline $\begin{array}{l}\text { Overall, I am } \\
\text { satisfied with } \\
\text { the system }\end{array}$ & $11 / 15$ & $\begin{array}{l}\text { 'Yes, I have been privileged to be part of this and my } \\
\text { boys are very keen to see it continue, they are sad to } \\
\text { see a bump in the road' (OA). } \\
\text { 'I miss them' (OA). } \\
\text { 'Worked well. Looked simple, non-intrusive. Was } \\
\text { flexible to accommodate Mum's needs' (SN) } \\
\text { Some respondents commented on different parts of the } \\
\text { system: } \\
\text { 'The multi-sensor was better for me than the smart plug } \\
\text { because it monitored both am and pm \& because I just } \\
\text { walked past it and it knew!' (OA) }\end{array}$ & $\begin{array}{l}\text { One person } \\
\text { disagreed } \\
\text { Three did } \\
\text { not reply } \\
\text { and one was } \\
\text { neutral. } \\
\text { The 'bump } \\
\text { in road' } \\
\text { was } \\
\text { stopping } \\
\text { project due } \\
\text { to lack of } \\
\text { funding. }\end{array}$ \\
\hline
\end{tabular}

Overall, strengthened relationships and widened networks with reduced levels of loneliness was a key reason for user satisfaction: "Daily monitoring strengthens our relationship. I like the 'not needing to worry' or feel undue concern" (SN) "It got my family involved in the project and expanded my network. It prompted my family to look into technologies that do this and what technologies are existing outside the project. It made me more enthusiastic about technology" (OA).

The respondent who was not satisfied with the system (Theme 4) had a system that suffered from several technical issues due to rurality which were difficult to work out and solve. This highlights that the main problems experienced with the prototype systems were technical in nature relating to connectivity issues and system resets after power 
surges and outages particularly with rurality. Using SD cards created problems with some systems but not with others, extensive exploration indicated that SD cards have limited ability to cope with multiple read/writes.

Additional functions were recommended by OAs and SNs such as an emergency option, detecting that the door was locked at night, using the flashing or static smart light, and its various colour options for many different functions such medication reminders or switching off the oven.

\section{Discussion}

This study explored how smart home technologies that connect OAs to their support networks could assist aging in place and enhance OAs' health and wellbeing. User requirements were identified in Phase 1 (Figure 2) and similar barriers to those previously identified in the literature were found [16-19] along with connectivity, power stability and interoperability. This project has shown that user requirements can be met, and barriers overcome. Scholars have warned against technofixing, whereby technology is proposed as a solution on its own without considering the broader social context [25], which advocates for a socio-technical systems approach [21] to the development of technologies. Although our findings from the prototyping are preliminary, one of the reasons why our system was utilized and positively evaluated could be that it was successfully grounded in the community by connecting OAs to their informal support networks. Furthermore, as the system allowed for individual customization and for oneto-many and many-to-many communication channels, rather than just the traditional patient-to-provider channel, the system could be tailored to the OA's needs, responsibilities among informal support network members could be shared, information needs could be delivered, and privacy could be respected.

At the same time, the possible negative consequences from a disregard of ethical issues should not be overshadowed. The need for the OA to be in control of their information was identified as a key user requirement. This highlights the advantage of being able to customize the system to the OA's requirements, but it also indicates the issue of giving informal support members access to personal information. As they are not registered healthcare practitioners, they are not bound to the same degree of regulation pertaining to the collection, storage, use, and disposal of personal information. Hence governance of this information in smart home telehealth systems is a critical area for further exploration. The success of the system was largely dependent on the OA's support network, requiring strong offline relationships, and so the system may not be suitable for all OAs. Nevertheless, our study has shown that the system can be successfully applied to improve the experience of aging in place by OAs who have existing support networks, by transferring information and facilitating communication.

A final key finding from this study is that OAs and their SNs did not recognise the potential for such a system to assist aging in place, until they have had the opportunity to experience it. Processes need to be established such that OAs and their SNs can become familiar with smart home technologies and experiment with their use to become more accustomed to the possibilities that smart home technology could bring prior to any purchasing decisions. These systems need to be scalable to changing requirements, hence limiting choice to separate ecosystems without interoperability restricts the ability of such systems to meet these requirements, reducing potential health and wellness outcomes from smart home telehealth systems. 
The study has some limitations. With the nature of qualitative research, the findings are not generalizable and so future research could investigate this topic with a wider scope. Participant recruitment was not drawn from a random sample of subjects, but it rather comprised individuals and organizations that actively volunteered to be involved in the study. The number of participants involved in the prototyping was limited and did not include the OAs' healthcare providers. The prototype demonstrated that smart home technologies can improve feelings of security, reduce loneliness and improve interpersonal communication but beyond that it did not explore specific health outcomes. Sensor systems lack quality clinical validation [15]. They must be tested and validated by health providers in real-life situations $[26,27]$. Thus, it is recommenced that further studies on health outcomes are conducted.

\section{Conclusion and lessons learnt}

This study shows that it is possible to design and implement low cost, scalable smart home telehealth systems that meet $\mathrm{OA}$ end-user requirements, improve feelings of security, reduce loneliness and improve interpersonal communication. Key findings are that OAs need to be in control of their information, interoperability is central, and determining governance of information is critical. OAs, and indeed their support networks, need time to experience smart home technologies to determine how best to use such technologies to meet their changing needs.

The next steps of this study are to expand the functionality of the system by interfacing further devices; explore ways to extend the connectivity of the system to incorporate connections to healthcare providers; to develop information governance principles; and to undertake further real-life trials to gain a better understanding of the impact of the system on the OA, their support network members and potential health and wellness outcomes.

Acknowledgements: This study was funded by the Health Research Council of New Zealand [reference number: 16/679].

\section{References}

[1] NZ Telehealth Forum \& Resource Centre. New Zealand: NZ Telehealth Forum \& Resource Centre. 2020. About Telehealth; n.d. Available from: https://www.telehealth.org.nz/.

[2] Coiera E. Guide to Health Informatics. $3^{\text {rd }}$ ed. Boca Raton, FL: CRC Press Taylor \& Francis Group. 2015. p. 710

[3] Susnea I, Dumitriu L, Talmaciu M, Pecheanu E, Munteanu D. Unobtrusive Monitoring the Daily Activity Routine of Elderly People Living Alone, with Low-Cost Binary Sensors. Sensors. MDPI AG; 2019 May; 16;19(10):2264. Available from: http://dx.doi.org/10.3390/s19102264

[4] Stats NZ. Wellington: Stats NZ; 2020. New Zealand's population could reach 6 million by 2050; [Cited 2020 Dec 11]. Available from https://www.stats.govt.nz/news/new-zealands-population-could-reach-6million-by-2050.

[5] OECD. Stat. Paris: Organisation for Economic Co-operation and Development. Health Status; [cited 2020 Dec 11]. Available from http://stats.oecd.org/index.aspx?DataSetCode=HEALTH_STAT

[6] Associate Minister of Health. Healthy ageing strategy. Wellington: Ministry of Health; 2016 [cited 2020 Dec 11]. p. 76. Available from https://www.health.govt.nz/system/files/documents/publications/healthy-ageingstrategy_june_2017.pdf 
[7] Ministry of Social Development. Wellington: Ministry of Social Development. Positive ageing goals and key actions; 2001 [cited 2020 Dec 11]. Available from https:/www.msd.govt.nz/about-msd-andour-work/publications-resources/planning-strategy/positive-ageing/goals-and-actions.html.

[8] Boldy D, Grenade L, Lewin G, Karol E, Burton E. Older people's decisions regarding 'ageing in place': A Western Australian case study. Australasian Journal on Ageing. 2011 Sept;30(3):136-142. Available from https://pubmed.ncbi.nlm.nih.gov/21923707/

[9] Wiles JL, Leibing A, Guberman N, Reeve J, Allen RE. The meaning of "aging in place" to older people. Gerontologist. 2012 Jun;52(3):357-66.

[10] Carretero S, Stewart J, Centeno C, Barbabella F, Schmidt A, Lamontagne-Godwin F, Lamura G. Can technology-based services support long-term care challenges in home care? Analysis of evidence from social innovation good practices across the EU: CARICT project summary report. European Commission. 2012 [cited 2020 Dec 11]. Available from doi:10.2791/43024

[11] Grace A, Gleasure R. Supporting the critical role of family carers in wellness management. Health Policy and Technology. 2017; 6(2):242-249. Available from doi:10.1016/j.hlpt.2017.04.002

[12] Canally C, Doherty S, Doran DM, Goubran RA. Using integrated bio-physiotherapy informatics in home health-care settings: A qualitative analysis of a point-of-care decision support system. Health Informatics Journal. 2015; 21(2):149-158.

[13] Loane J, O’Mullane B, Bortz B, Knapp RB. Looking for similarities in movement between and within homes using cluster analysis. Health Informatics Journal. 2012;18(3):202-211.

[14] Wolters MK, Kelly F, Kilgour J. Designing a spoken dialogue interface to an intelligent cognitive assistant for people with dementia. Health Informatics Journal. 2016;22(4):854-866.

[15] Hunter IM, Lockhart CA. Use of sensor data to support interRAI assessments of older adults living at home in New Zealand. Palmerston North: Massey University, 2020 for NZ Ministry of Health.

[16] Peek ST, Wouters EJ, van Hoof J, Luijkx KG, Boeije HR, Vrijhoef HJ. Factors influencing acceptance of technology for aging in place: a systematic review. Int J Med Inform. 2014 Apr;83(4):235-48. Available from doi: 10.1016/j.ijmedinf.2014.01.004.

[17] Peek ST, Luijkx KG, Rijnaard MD, Nieboer ME, van der Voort CS, Aarts S, van Hoof J, Vrijhoef HJ, Wouters EJ. Older Adults' Reasons for Using Technology while Aging in Place. Gerontology. 2016;62(2):226-37. Available from doi: 10.1159/000430949.

[18] Yusif S, Soar J, Hafeez-Baig A. Older people, assistive technologies, and the barriers to adoption: A systematic review. Int J Med Inform. 2016 Oct;94:112-6. Available from doi: 10.1016/j.ijmedinf.2016.07.004.

[19] Joshi A, Thorpe L, Waldron L. Population Health Informatics. Driving Evidence-Based Solutions into Practice. Massachusetts: Jones \& Bartlett Learning; 2019

[20] Department of Internal Affairs. The Digital Inclusion Blueprint, Te Mahere mō te Whakaurunga Matihiko. Wellington: Department of Internal Affairs. 2019. p. 24 Available from http://www.digital.govt.nz

[21] Coiera E. Putting the technical back into socio-technical systems research. International Journal of Medical Informatics. 2007;76, S98-S103.

[22] Elers P, Hunter I, Whiddett D, Lockhart C, Guesgen H, Singh A. User Requirements for Technology to Assist Aging in Place: Qualitative Study of Older People and Their Informal Support Networks. JMIR Mhealth Uhealth 2018;6(6):e10741. Available from doi:10.2196/10741

[23] Hunter I, Elers P, Lockhart C, Guesgen H, Singh A, Whiddett D. Issues associated with the Management and Governance of Sensor Data and Information to Assist Aging in Place: Focus Group Study With Health Care Professionals. JMIR Mhealth Uhealth 2020;8(12):e24157.

[24] Whiddett D, Hunter I, Elers P, Lockhart C, Guesgen H, Singh A. New and Emerging Issues for Technologies to Support Older Adults to Age in Place: Findings From a Workshop of Experts. International Journal of Applied Research on Public Health Management. 2021;Jan-Jun;6(1).

[25] Dutta MJ, Kaur-Gill S. Precarities of migrant work in Singapore: Migration, (im)mobility, and neoliberal governmentality. International Journal of Communication (19328036). 2018;12.

[26] Pantelopoulos A, Bourbakis. NG. A Survey on Wearable Sensor-Based Systems for Health Monitoring and Prognosis. IEEE Transactions on Systems, Man, and Cybernetics, Part C (Applications and Reviews). 2010;40(1): p. 1-12. Available from https://ieeexplore.ieee.org/document/5306098

[27] Robinson NL, Cottier TV, Kavanagh DJ. Psychosocial Health Interventions by Social Robots: Systematic Review of Randomized Controlled Trials. J Med Internet Res. 2019 May 10;21(5):e13203. 